\title{
Paramagnetic Centres in Oxidised Coal
}

\author{
L. Najder-Kozdrowska ${ }^{a, *}$, R.I. Samoilova ${ }^{b}$, R. Kappl ${ }^{c}$, J. HÜttermann ${ }^{c}$ \\ AND A.B. WIĘCKOWSKI ${ }^{a}$ \\ ${ }^{a}$ Institute of Physics, Faculty of Physics and Astronomy, University of Zielona Góra \\ Szafrana 4a, 65-516 Zielona Góra, Poland
}

${ }^{b}$ Institute of Chemical Kinetics and Combustion, Russian Academy of Sciences, Novosibirsk 630090, Russia

${ }^{c}$ Institute of Biophysics, Faculty of Medicine, University of Saarland, 66421 Homburg (Saar), Germany

This paper comprises the results obtained by continuous wave $(\mathrm{cw}) /$ pulse electron paramagnetic resonance spectroscopy for oxidised coals. The values of EPR linewidths are different for samples of coal treated by different chemical agents. The asymmetric EPR line shape indicates to complex composition of paramagnetic centres in coal. In coal oxidised by $\mathrm{HNO}_{3}$ big changes of linewidth with temperature were observed. For all samples the spin-lattice relaxation time $T_{1}$ was determined by pulse EPR method. The correlation between used chemical agents and the value of $T_{1}$ was established.

PACS numbers: 33.35.+r, 61.66.Hq, 76.30.Rn, 89.30.ag

\section{Introduction}

Coal possesses a high concentration of paramagnetic centres and gives the possibility to use different methods based on the electron paramagnetic resonance phenomena for study of radicals, their structure and dynamics. Although the cw-EPR spectra of coal at X-band look like single lines, their multi-component character was proved $[1,2]$. Because of complex chemical structures of coal, there exist a few groups of paramagnetic centres [3-5]. The EPR spectrum of coal is superposition of a few Gaussian and Lorentzian lines [1, 2]. For broad component lines in the EPR spectrum, paramagnetic centres in structures consisting of a few aromatic rings and aliphatic units are responsible, whereas for narrow EPR component lines, paramagnetic centres in multi-ring aromatic structures with delocalized $\pi$ electrons.

The EPR study gives the possibility to discuss the line shape and other EPR parameters (linewidth $\Delta B_{\mathrm{pp}}$, spectroscopic splitting factor $g$ ). The multi-component character of EPR spectra of coal has been investigated not only by us, but also by other researchers. In the work of Haruo et al. [6] an analysis of EPR parameters for component lines in heated coal was made. The authors deconvoluted EPR spectra into three components and they analysed concentration of paramagnetic centres connected with these component lines. In the work made by Ryabikin et al. [7] an analysis of vegetable materials with carbon content in the range $40-85 \%$ after carbonization in the temperature range $100-800^{\circ} \mathrm{C}$ was performed. The authors have discussed the linewidth of EPR signal and the concentrations of paramagnetic centres. Recently a paper written by Tian et al. [8] appeared on EPR study of radicals occurring during coal combustion. Results obtained by us in this paper give information on groups of paramagnetic centres existing in oxidised samples. The kinds of EPR line shapes of paramagnetic centres responsible for individual lines were shown. This work is a continuation of our earlier results in this field and makes the subject to become completed. The oxidation process leads to lowering the sulphur content in coal and is used for its desulphurisation.

According to Wachowska et al. [9-12] oxidation of sulphur in coal under mild conditions leads to formation of sulphoxides, sulphones and sulphonic acid which can be partially removed by water. As mild condition we treat the oxidation by nitric acid $\mathrm{HNO}_{3}$, by peroxyacetic acid (PAA) $\mathrm{H}_{3} \mathrm{C}(\mathrm{CO}) \mathrm{OOH}$, and by oxygen $\mathrm{O}_{2}$ in a water solution of disodium carbonate $\mathrm{Na}_{2} \mathrm{CO}_{3}$ [9-12]. Demineralised coal samples were used by us for oxidation to avoid reaction of sulphur with the mineral substance, e.g. calcium compounds. Because coal consists of an aromatic rings system, nitric acid does not only oxidise the coal system but also nitrates the rings. After oxidation of coal the number of methylene $-\mathrm{CH}_{2}-$ functional groups decreases, whereas the number of oxygen - $\mathrm{O}$ - groups increases. We await that the EPR method will give us interesting information on the parameters describing the relaxation processes in oxidised coal. This work and an earlier one [13] show that the EPR spectra parameters depend on the chemical agent used for oxidation. The aim of this work was to obtain knowledge of the groups of paramagnetic centres existing in coal and samples modified by chemical agents. We have also determined the relaxation times $T_{1}$ for oxidised coal samples.

* corresponding author; e-mail: lkozdrowska@wp.pl 


\section{Method}

\subsection{Continuous wave (cw) method}

The EPR measurements were performed with an X(9.4 GHz)-band cw BRUKER-spectrometer. The EPR spectra in X-band were recorded at $8 \mathrm{~K}, 30 \mathrm{~K}$ and $300 \mathrm{~K}$ for different microwave powers applied during experiment.

\subsection{Pulse method}

Measurements were performed with BRUKER ELEXSYS 580 EPR spectrometer. A two-pulse echo experiment $(\pi / 2-\tau-\pi-\tau$ echo $)$ was used to measure field swept echo signal in X-band. For determination of the longitudinal relaxation time, $T_{1}$, the three-pulse inversion saturation recovery experiment $(\pi-\tau-\pi / 2-\tau-\pi-\tau$ echo) was used.

\section{Samples}

The low-rank flame coal proposed for the study comes from the "Siersza" mine (Poland). The proximate analysis of raw coal gave $11.1 \%$ ash, $7.8 \%$ moisture, and $37.8 \%$ $\mathrm{V}$ (daf) (daf = dry ash free) volatile matter. This coal was demineralised using hydrochloric $\mathrm{HCl}$ and hydrofluoric HF acids according to the procedure of Radmacher and Mohrhauer [14]. The ultimate/chemical/elemental analysis of the demineralised coal gave $73.8 \% \mathrm{C}$ (daf), $4.7 \% \mathrm{H}$ (daf), $1.1 \% \mathrm{~N}$ (daf), $0.5 \% \mathrm{~S}$ (daf), and $19.9 \% \mathrm{O}$ (daf). The coal was treated with chemical agents and finally for the researches samples were used as follows: raw coal, demineralised coal, which was in next step oxidised by $5 \%$ nitric acid $\mathrm{HNO}_{3}$ solution at the boiling point, by peroxyacetic acid (PAA) $\mathrm{H}_{3} \mathrm{C}(\mathrm{CO}) \mathrm{OOH}$ (a mixture of acetic acid $\mathrm{H}_{3} \mathrm{CCOOH}$ and dihydrogen dioxide $\mathrm{H}_{2} \mathrm{O}_{2}$ ) at $40{ }^{\circ} \mathrm{C}$, and by gaseous oxygen $\mathrm{O}_{2}$ in atmospheric air in a water solution of $0.5 \mathrm{~N}$ disodium carbonate $\mathrm{Na}_{2} \mathrm{CO}_{3}$ at a temperature of $80^{\circ} \mathrm{C}$ (all oxidation processes were performed during $6 \mathrm{~h}$ ). Details of the processing have been described in the works $[9,10]$. The coal samples were evacuated in vacuum of $10^{-4}$ Torr and sealed in glass tubes.

\section{Results and discussion}

The experiment at cw-EPR for X-band comprises measurements at room temperatures versus microwave power. The line shape of recorded EPR spectra is asymmetric which changes with value of microwave power. It suggests that there exist a few groups of paramagnetic centres in coal $[1,2,13,15]$. With increase of microwave power some component lines saturated and in this situation another component line becomes dominating in this EPR spectrum. A trial was made to explain this problem in the works $[1,2]$. The fitting of experimental data for $\mathrm{X}$-band obtained at room temperature was made by superposition of Gaussian and Lorentzian lines for all used samples. The best result was obtained for combination of four-component lines (broad Gaussian line $G$, broad Lorentzian line $L 1$, narrow Lorentzian $L 2$ line, and narrow Lorentzian $L 3$ line). The coal treatment by chemical agents did not change the number of component lines. After demineralization the decrease of value of $g$-factor was noticed for all component lines of EPR spectra.

The parameters for component lines are presented in Table I. In the EPR spectra for all samples of coal and oxidised coals being under investigation, single lines with nearly equal $g$-factors and different linewidths $\Delta B_{\mathrm{pp}}$ were observed during EPR measurements at $8 \mathrm{~K}, 30 \mathrm{~K}$, and $300 \mathrm{~K}$.

TABLE I

$g$-factor and linewidth $\Delta B_{\mathrm{pp}}$ for component EPR lines for coal.

\begin{tabular}{l|c|c|c|c|c|c|c|c}
\hline \hline \multicolumn{1}{c|}{ Component EPR lines } & \multicolumn{2}{c|}{ Gaussian } & \multicolumn{2}{c|}{ Lorentzian 1 } & \multicolumn{2}{c|}{ Lorentzian 2} & \multicolumn{2}{c}{ Lorentzian 3 } \\
\hline \multicolumn{1}{c|}{ Samples Parameters } & $g$ & $\begin{array}{c}\Delta B_{\mathrm{pp}} \\
{[\mathrm{mT}]}\end{array}$ & $g$ & $\begin{array}{c}\Delta B_{\mathrm{pp}} \\
{[\mathrm{mT}]}\end{array}$ & $g$ & $\begin{array}{c}\Delta B_{\mathrm{pp}} \\
{[\mathrm{mT}]}\end{array}$ & $\begin{array}{c}\Delta B_{\mathrm{pp}} \\
{[\mathrm{mT}]}\end{array}$ \\
\hline raw coal & 2.0033 & 0.97 & 2.0030 & 0.48 & 2.0029 & 0.16 & 2.0026 & 0.03 \\
coal demineralised by HCl/HF & 2.0027 & 0.81 & 2.0028 & 0.43 & 2.0026 & 0.16 & 2.0024 & 0.03 \\
coal oxidised by $\mathrm{HNO}_{3}$ & 2.0030 & 0.64 & 2.0032 & 0.33 & 2.0029 & 0.17 & 2.0027 & 0.04 \\
coal oxidised by $\mathrm{PAA}_{\text {coal oxidised by } \mathrm{O}_{2} / \mathrm{Na}_{2} \mathrm{CO}_{3}}$ & 2.0031 & 1.24 & 2.0030 & 0.48 & 2.0028 & 0.19 & 2.0027 & 0.09 \\
& 2.0026 & 0.79 & 2.0029 & 0.45 & 2.0026 & 0.19 & 2.0024 & 0.06
\end{tabular}

The parameters of these EPR spectra (linewidth $\Delta B_{\mathrm{pp}}$, and $g$-factor) are presented in Table II. The EPR spectrum obtained for sample treated with $\mathrm{HNO}_{3}$ show an increase of linewidth $\Delta B_{\mathrm{pp}}$ with decrease of measurements temperature in comparison with the EPR spectrum of raw coal, demineralised coal and oxidised by 
$\mathrm{O}_{2} / \mathrm{Na}_{2} \mathrm{CO}_{3}$, whereas the EPR spectrum obtained for oxidised coal with PAA show a decrease of the linewidth $\Delta B_{\mathrm{pp}}$. For other samples the changes are not so sharp and for temperatures $8 \mathrm{~K}, 30 \mathrm{~K}$ and $300 \mathrm{~K}$ they are nearly the same. The $g$-factor does not change significantly (Table II). Figure 1 shows EPR spectra recorded for sample of coal oxidised by $\mathrm{HNO}_{3}$ at temperatures of $8 \mathrm{~K}$, $30 \mathrm{~K}$ and $300 \mathrm{~K}$. With decreasing the microwave power, a small shift of $g$-factor to higher values for all samples was observed. The considerable decrease of the value of the $g$-factor with increase of microwave power can be explained in the following way. One of the EPR component lines, which are well visible at lower microwave power, has a well-defined $g$-factor. This component of EPR spectra dominates in spectra recorded at lower microwave powers. With increase of microwave power this component saturated and in this situation another component of EPR line becomes dominant in the spectrum. The $g$-factor determined from experimental spectra is in- termediate between values characteristic for the lowest and the highest microwave power.

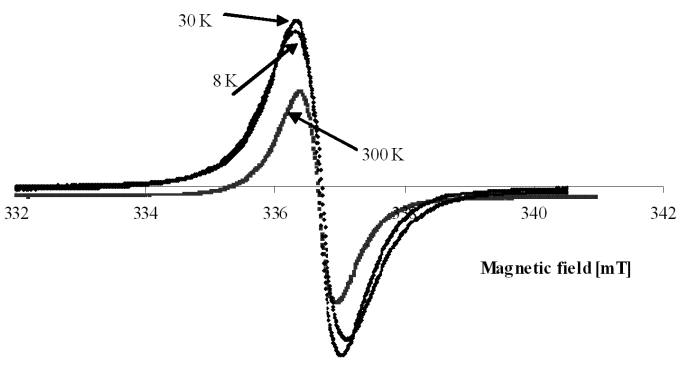

Fig. 1. EPR spectra of oxidised coal by $\mathrm{HNO}_{3}$ recorded by continuous wave method at $X$-band for $8 \mathrm{~K}$, $30 \mathrm{~K}$ and $300 \mathrm{~K}$.

TABLE II

The values of spectroscopic splitting factors $g$ and linewidth $\Delta B_{\mathrm{pp}}$ obtained for experimental spectra of coal samples at $8 \mathrm{~K}, 30 \mathrm{~K}$ and $300 \mathrm{~K}$.

\begin{tabular}{l|c|c|c|c|c|c}
\hline \hline Temperature of EPR measurements & \multicolumn{2}{|c|}{$8 \mathrm{~K}$} & \multicolumn{2}{c|}{$30 \mathrm{~K}$} & \multicolumn{2}{c}{$300 \mathrm{~K}$} \\
\hline Samples & $g$ & $\begin{array}{c}\Delta B_{\mathrm{pp}} \\
{[\mathrm{mT}]}\end{array}$ & $g$ & $\begin{array}{c}\Delta B_{\mathrm{pp}} \\
{[\mathrm{mT}]}\end{array}$ & $g$ & $\begin{array}{c}\Delta B_{\mathrm{pp}} \\
{[\mathrm{mT}]}\end{array}$ \\
\hline Parameters of EPR spectra & 2.0027 & 0.23 & 2.0024 & 0.24 & 2.0028 & 0.27 \\
coal demineralised by HCl/HF & 2.0028 & 0.24 & 2.0025 & 0.24 & 2.0027 & 0.28 \\
coal oxidised by $\mathrm{HNO}_{3}$ & 2.0029 & 0.80 & 2.0028 & 0.70 & 2.0028 & 0.57 \\
coal oxidised by $\mathrm{PAA}_{\text {coal oxidised by } \mathrm{O}_{2} / \mathrm{Na}_{2} \mathrm{CO}_{3}}^{2.0029}$ & 0.12 & 2.0028 & 0.16 & 2.0028 & 0.18 \\
& 2.0030 & 0.28 & 2.0029 & 0.28 & 2.0029 & 0.27
\end{tabular}

The EPR spectrum at $Q$-band for raw coal was also recorded (Fig. 2). The aim of the cw-EPR measurements at Q-band was to obtain better resolution of the EPR spectra, which might be useful for further study of multi-component EPR spectra of coal. This experiment has shown a broader linewidth of spectra than at X-band. The broadening of linewidth has its source not only in change of frequency during measurements but also it is caused by contact of sample with air. The change in linewidth might be interpreted by the dispersion of different groups of paramagnetic centres in coal, which have some statistical distribution of $g$-value, which can reveal as increase of linewidth in EPR spectra [16].

Measurements by pulse EPR technique at X-band (two-pulse field swept electron spin echo (ESE) experiment and inversion saturation recovery experiment) were performed. All ESE measurements were made at room temperature. The shapes of recorded spectra are very different for studied samples. This is caused by influence

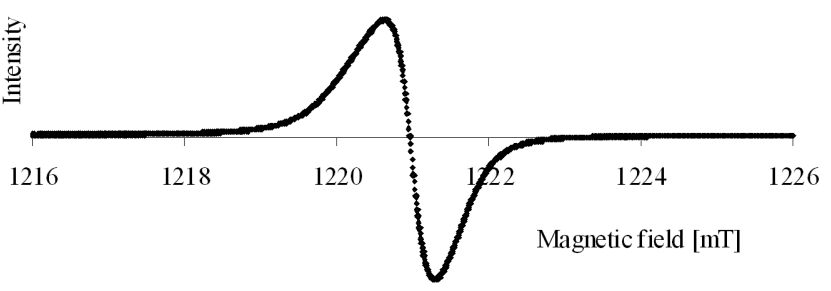

Fig. 2. EPR spectrum of raw coal after contact with air recorded by continuous method at $Q$-band.

of chemical agents used during samples preparation. The field swept ESE spectra in two-pulse experiment for all samples are shown in Fig. 3. The simplest spectrum was obtained for raw coal. For the treated, oxidised samples there occurred a strong oscillation on the echo signal. This is more easily detected for sample treated by 


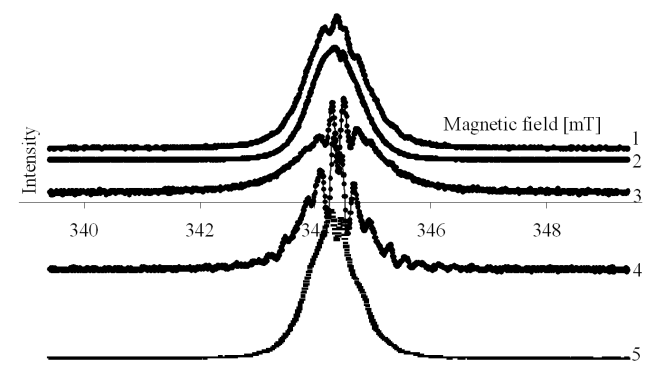

Fig. 3. Field swept ESE, two-pulse field swept echo detected spectra. 1 - raw coal, $2-\mathrm{HCl} / \mathrm{HF}, 3-\mathrm{HNO}_{3}$, $4-\mathrm{PAA}, 5-\mathrm{O}_{2} / \mathrm{Na}_{2} \mathrm{CO}_{3}$.

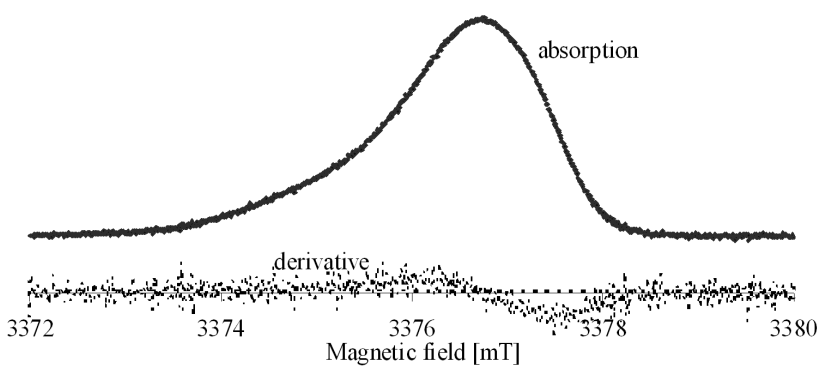

Fig. 4. $W$-band field swept 2-pulse ESE signal (absorption and derivative) for raw coal after contact of sample with air.

PAA (curve \#4 in Fig. 3). These oscillations completely disappear by subtracting the signal in two steps with phase cycling. It means that these oscillations are coming from strong free induction decay (FID) signal after second pulse, which overlaps with the echo signal. It is reasonable to suggest that this FID signal is caused by the availability of the existence of a very narrow line, which overlaps with normal coal signal. The inversion saturation recovery experiment gave the possibility to measure the relaxation time $T_{1}$ for each sample. In this experiment we can also see how big is the influence of the kind of oxidizing agents on the relaxation time $T_{1}$. From the data presented in Table III the influence of the chemical agent on the $T_{1}$ value can be seen. The highest value of $T_{1}$ is for raw coal and the smallest for samples treated with $\mathrm{HNO}_{3}$. The oxidation of coal caused a shortening of relaxation times $T_{1}$ in coal samples. The biggest shortening is observed for samples oxidised with $\mathrm{HNO}_{3}$, next by $\mathrm{H}_{3} \mathrm{C}(\mathrm{CO}) \mathrm{OOH}(\mathrm{PAA})$ and by $\mathrm{O}_{2} / \mathrm{Na}_{2} \mathrm{CO}_{3}$. This is in agreement with the results of Kozłowski et al. [9] for changes in sulphur groups in the case of oxidation of coal. Some correlation between the used agent and the value of relaxation time $T_{1}$ can be noticed (Table III). The relaxation time $T_{1}$ decreases for coal samples in the order: raw $>$ demineralized $>\mathrm{O}_{2} / \mathrm{Na}_{2} \mathrm{CO}_{3}>\mathrm{PAA}>\mathrm{HNO}_{3}$. It can be seen that the stronger the oxidative properties of the agent used, the shorter is the relaxation time $T_{1}$.

The aim of measurements performed at $W$-band was to obtain better resolution of spectra. The spectrum of
TABLE III

Relaxation time $T_{1}$ for studied samples.

\begin{tabular}{l|c}
\hline \hline \multicolumn{1}{c|}{ Sample } & $T_{1}[\mu \mathrm{s}]$ \\
\hline raw coal & 53.7 \\
coal demineralised by $\mathrm{HCl} / \mathrm{HF}$ & 39.1 \\
coal oxidised by $\mathrm{HNO}_{3}$ & 3.16 \\
coal oxidised by $\mathrm{PAA}_{\text {coal oxidised by } \mathrm{O}_{2} / \mathrm{Na}_{2} \mathrm{CO}_{3}}$ & 27.5 \\
& 33.0
\end{tabular}

raw coal (after contact with air) for two-pulse field swept experiment at $W$-band shows a single line with asymmetric shape (Fig. 4). It can suggest the existence of anisotropy of the $g$-factor or/and a small hyperfine splitting. No resolved lines are visible. It is caused by influence of paramagnetic molecules of oxygen which leads to broadening of recorded EPR spectrum. The obtainment of better resolution of EPR spectra would be very helpful in recognition and explanation of the nature of paramagnetic centres in coal. The $W$-band experiment has not confirmed our suggestion about overlapping broad line with sharp line.

\section{Conclusions}

The used chemical agents $\left(\mathrm{HNO}_{3}, \mathrm{H}_{3} \mathrm{C}(\mathrm{CO}) \mathrm{OOH}\right.$ (PAA), $\mathrm{O}_{2} / \mathrm{Na}_{2} \mathrm{CO}_{3}$ ) for oxidation of coal do not influence the number of component lines in the recorded EPR spectra, but they change the EPR parameters (linewidth $\Delta B_{\mathrm{pp}}, g$-factor). The oxidation agents affect the values of relaxation time $T_{1}$ of paramagnetic centres in coal. The biggest influence on the EPR spectra was observed for coal sample treated with $\mathrm{HNO}_{3}$ and the lowest for sample treated with $\mathrm{O}_{2} / \mathrm{Na}_{2} \mathrm{CO}_{3}$.

\section{Acknowledgments}

The authors thank Professor Dr. Helena Wachowska and Dr. Robert Pietrzak from Faculty of Chemistry, Adam Mickiewicz University in Poznań, for providing us with coal samples being under investigation, and L. Najder-Kozdrowska is highly indebted to the Deutsche Forschungsgemeinschaft DFG in Bonn, for granting a fellowship.

\section{References}

[1] L. Kozdrowska, B. Pilawa, A.B. Więckowski, Fuel Process. Technol. 85, 1585 (2004).

[2] B. Pilawa, A.B. Więckowski, M. Kozłowski, H. Wachowska, Nukleonika 42, 447 (1997).

[3] D.W. van Krevelen, Coal. Typology, Chemistry, Constitution, 3rd ed., Elsevier, Amsterdam 1993.

[4] A. Marzec, Fuel Process. Technol. 77-78, 25 (2002).

[5] O. Ito, H. Seki, M. Iino, Bull. Chem. Soc. Jpn. 60, 2967 (1987). 
[6] K. Haruo, S. Izumi, H. Yasuyuki, Tetsu to Hagane 92, $122(2006)$.

[7] Y.A. Ryabikin, M.M. Yemuranov, O.V. Zashkvara, M.A. Biisenbaev, T.A. Shabanova, Z.A. Mansurov, Appl. Magn. Reson. 35, 231 (2008).

[8] L. Tian, C.P. Koshland, J. Yano, V.K. Yachandr, I.T.S. Yu, S.C. Lee, D. Lucas, Energy Fuels 23, 2523 (2009).

[9] M. Kozłowski, R. Pietrzak, H. Wachowska, J. Yperman, Fuel 81, 2397 (2002).

[10] R. Pietrzak, H. Wachowska, Fuel 82, 705 (2003).

[11] M. Kozłowski, R. Pietrzak, H. Wachowska, J. Yperman, J. Therm. Anal. Calorim. 75, 125 (2004).
[12] R. Pietrzak, M. Kozłowski, H. Wachowska, J. Yperman, Cent. Eur. J. Chem. 2, 278 (2004).

[13] B. Pilawa, A.B. Więckowski, R. Pietrzak, H. Wachowska, Cent. Eur. J. Chem. 5, 330 (2007).

[14] W. Radmacher, P. Mohrhauer, Brennstoff-Chemie 37, 353 (1956).

[15] B. Pilawa, A.B. Więckowski, R. Pietrzak, H. Wachowska, Fuel 81, 1925 (2002).

[16] P.B. Sczaniecki, A.B. Więckowski, H. Wachowska, M. Kozłowski, in: Radio- and Microwave Spectroscopy, Ed. N. Piślewski, Series Physics Vol. 67, Adam Mickiewicz University Scientific Press, Poznań 1991, p. 259. 